b. Patients who underwent primary closure had significantly shorter times to first feed and a shorter durationof parenteral nutrition.

This study describes our practice and contributes to the growing pool of data regarding gastroschisis. In the absence of consensus, this may aid management decisions and reduce adverse outcomes.

\section{G141(P) TRANSFORMING CULTURE}

S Mohamed Cassim. Neonatal Unit, Aberdeen Maternity Hospital, NHS Grampian, Aberdeen, UK

\subsection{6/archdischild-2018-rcpch.137}

Background Trainee led initiative in response to National Training Survey (NTS) reflecting disengagement and disenchantment among trainees.

Aim To set up a Trainee Forum in a Neonatal Intensive Care Unit, which would be chaired by the senior trainees. The purpose was to identify trainee issues in a timely manner and highlight them to trainers, clinical director, deanery and the medical education team.

Methods A bi-monthly, closed meeting for trainees was established. Issues raised included improving teaching structure, postnatal ward set up, handover, valuing trainees and prioritising training needs. This was fed back by the senior trainee at the departmental Senior Staff Meeting. Working groups to target the different areas were established. Sessions with the 'Workplace Behaviour Champion' were organised to support and empower trainees. Trainee experience was measured at six months using PHEEM (Postgraduate Hospital Educational Environment Measure) and at twelve months on the NTS.

Results A joint medical/nursing education group was set up, resulting in revision of the teaching schedule and simulation. A 'What's on' bulletin of teaching opportunities was emailed out weekly. Teaching sessions were also highlighted at staff handovers. The handover structure was revised. A Quality Improvement(QI) project was established, reviewing ward rounds to maximise training opportunities. Positive behaviours were reinforced and mentoring was provided for trainees by senior trainees, management and the deanery. 'Baby-check' clinics were also set up as a QI project. The PHEEM questionnaire demonstrated improvement in some areas at six months, particularly in availability of training opportunities, education and morale. This was sustained on the NTS survey at 12 months.

Conclusions The Trainee Forum was successful in bringing all staff groups together as a team and motivating them to be the vehicles of change. This is an ongoing project with continuous feedback in real time from trainees. This multi-prong approach has demonstrated improvement in training on initial survey. Changing attitudes can be challenging but this process continues to engage trainees, consultants and managers towards modelling a positive work environment. It has also provided a platform for senior trainees to be involved in clinical leadership and engage with managers in a very meaningful way.

\section{Child Protection Special Interest Group}

\section{G142 FEMALE GENITAL MUTILATION SURVEILLANCE IN UNDER 16 YEARS OLDS IN THE UK AND IRELAND}

${ }^{1} \mathrm{~N}$ Ayadi O'Donnell, ${ }^{2} \mathrm{M}$ Leoni, ${ }^{3} \mathrm{G}$ Debelle, ${ }^{4} \mathrm{R}$ Lynn, ${ }^{5} \mathrm{~A}$ Armitage, ${ }^{5} \mathrm{SM}$ Creighton, ${ }^{6} \mathrm{R}$ Viner, ${ }^{5} \mathrm{D}$ Hodes. ${ }^{1}$ Department of Paediatrics, Whittington Hospital NHS Trust, London, UK; ${ }^{2}$ Research and Policy Division, Royal College of Paediatrics and Child Health, London, UK; ${ }^{3}$ Department of Paediatrics, Birmingham Women and Children's Hospital NHS Foundation Trust, Birmingham, UK; ${ }^{4}$ British Paediatric Surveillance Unit, Royal College of Paediatrics and Child Health, London, UKi ${ }^{5}$ Department of Paediatrics, University College London Hospitals NHS Foundation Trust, London, UK; ${ }^{6}$ Institute of Child Health, University College London, London, UK

\subsection{6/archdischild-2018-rcpch.138}

Aims Female genital mutilation (FGM) is the name given to procedures that involve partial or total removal or other injury to the female genitalia for nonmedical reasons. This study describes the presentation, incidence and clinical management of children with FGM in the UK and Republic of Ireland (ROI).

Methods Cases of FGM were reported using the established national British Paediatric Surveillance Unit (BPSU) reporting system. The data period is from November 2015-November 2017 with a 12 month follow up.

Results These interim results are from 120 cases reported (November 2015-September 2017). 61 (51\%) had confirmed FGM, 18 cases were reported in error or were duplicates, 36 questionnaires were incomplete [5 did not meet case definition]. $48 \%(n=29)$ of the 61 confirmed cases were classified as type 2.

In over $72 \%$ of the 61 cases, the parent disclosed child's history of FGM. At the time of diagnosis, $80 \%$ of children $(n=49)$ were four years or older (11 cases not recorded). Most children were diagnosed between 5 years and 10 years 11 months $(n=27)$ or 11 years and 15 years 11 months $(n=20)$ with 3 cases diagnosed between 0 and 4 years 11 months. In $51 \%$ of cases FGM was said to have been performed when the child was between 0 and 3 years $(n=31)$. $93 \%(n=57)$ were performed before arrival to the UK.

$13 \%(n=8)$ of children had medical symptoms attributed to FGM, with $7 \%(n=4)$ of children identified to have mental health symptoms relating to FGM. No children presented with a history of labiaplasty or genital piercing.

Conclusion Numbers reported were lower than expected for UK estimated prevalence with fewer physical and mental health symptoms than anticipated. Further information is needed to determine illegality under UK law. These findings should be used to educate health, social care, police and education on prevention programmes to help influence national policies.

\section{G143 HEAD TRAUMA IN UNDER 2'S - ACCIDENTAL VS INFLICTED?}

${ }^{1} \mathrm{G}$ Campbell, ${ }^{1} \mathrm{~S}$ McCallion, ${ }^{2} \mathrm{O}$ Kiuru, ${ }^{2} \mathrm{~S}$ Foster. ${ }^{1}$ Royal Hospital for Children, Glasgow, UK; ${ }^{2}$ Medical School, University of Glasgow, UK

10.1136/archdischild-2018-rcpch.139 
Background Head injury is a common presenting complaint to emergency departments and can generate clinical concern regarding non accidental injury (NAI) in young children. Clinicians are wary of exposing young children to unnecessary radiation but must balance this risk with their duty to protect the child and recognise abuse.

Objective To review all radiological imaging for trauma related head injuries in under- 2 year olds with the aim of establishing the incidence of non-accidental injury and identify associated features that may aid clinical decision making.

Design A single-centre retrospective note review was conducted over a 3 year period $(01 / 01 / 12$ - 01/01/2015) of children $<2$ years of age who presented to a tertiary paediatric hospital (RHSC, Glasgow) and received cranial imaging. Cases were identified using the PACS reporting system.

Results 75 cases were identified as trauma related neuroimaging over the study period and were subject to a detailed case note review. Median age was 39 weeks. There was a male predominance of $65 \%$. All 75 patients underwent CT head as their primary mode of trauma imaging.

Abnormal findings were reported in $79 \%$ with the most common finding being unilateral parietal skull fracture. $44 \%$ of those with positive findings on CT underwent a skeletal survey and 36\% had ophthalmology review. 31\% had a social work strategy meeting prior to discharge.

$17 \%$ of patients with positive findings on CT head were deemed to have sustained their injury secondary to abuse. None of these injuries were witnessed. Median age was 16 weeks. $70 \%$ of inflicted injuries had a complex skull fracture compared to $18 \%$ for those deemed accidental. $20 \%$ of the NAI group were previously known to social work compared to $3 \%$ in the accidental group.

Conclusion CT is the modality of choice for suspected skull fracture in RHSC, Glasgow. Younger age, unwitnessed injury, existing social work support and complex skull fracture were all associated more commonly with abusive injuries in this 3 year review. Our data has contributed to a larger UK study aiming to determine national variation in practice and deriving a clinical decision making tool to exclude/diagnose NAI as the cause of skull fracture.

\section{G144 PEER REVIEW EVALUATION AND NATIONAL GUIDELINE COMPARISON}

A Roberts, A Mandal, L Peers. Safeguarding, Sheffield Children's Hospital, Sheffield, UK

10.1136/archdischild-2018-rcpch. 140

Aims Peer review in child protection is an important aspect of reflective practice. It aims to impartially evaluatethe work of others, improving the quality of care. ${ }^{1}$

The RCPCH recommends organising and documenting monthly peer review meetings, lead by a chairperson.

This audit was designed to compare the current peer review system with the RCPCH national guidelines therefore highlighting areas of potential improvement within the peer review system.

Methods Stage 1 - Peer review forms from August 2014 to July 2015 were evaluated and compared to national $\mathrm{RCPCH}$ guidelines to look for possible areas of improvement. Following the initial audit, several recommendations were made; the peer review form was redesigned and a single chairperson was suggested.
Stage 2 - Peer review forms were evaluated from January 2016 to December 2016 to compare the effectiveness of the new form and to look for any further improvements in peer review.

Results From August 2014 to July 2015, peer review forms were insufficiently completed. Following the redesign of the form the documentation of peer review meetings improved (table 1).

\begin{tabular}{|c|c|c|c|c|}
\hline Question & $\begin{array}{l}\text { Audit, } \\
2014 / \\
2015\end{array}$ & $\begin{array}{l}\text { Audit, } \\
2014 / \\
2015\end{array}$ & $\begin{array}{l}\text { Re- } \\
\text { audit, } \\
2016\end{array}$ & $\begin{array}{l}\text { Re- } \\
\text { audit,2016 }\end{array}$ \\
\hline & Yes & No & Yes & No \\
\hline $\begin{array}{l}\text { Do peer review meetings occur every } \\
\text { week? }\end{array}$ & $88 \%$ & $12 \%$ & $82 \%$ & $18 \%$ \\
\hline $\begin{array}{l}\text { Are minutes recorded at every } \\
\text { meeting and are attendees always } \\
\text { listed? }\end{array}$ & $100 \%$ & $0 \%$ & $100 \%$ & $0 \%$ \\
\hline $\begin{array}{l}\text { Is a member of the CAU team } \\
\text { present to chair the meeting? }\end{array}$ & $93 \%$ & $7 \%$ & $100 \%$ & $0 \%$ \\
\hline Is the lead consultant present?* & $79 \%$ & $2 \%$ & $93 \%$ & $5 \%$ \\
\hline $\begin{array}{l}\text { During the meeting itself, is a } \\
\text { general consensus always reached? }\end{array}$ & $64 \%$ & $36 \%$ & $83 \%$ & $17 \%$ \\
\hline
\end{tabular}

* In 2014/2015, 19\% of meetings did not record the presence of a lead consultant. In $2016,2 \%$ of meetings did not record the presence of a lead consultant.

Conclusion The simple measure of changing the peer review form has improved the documentation of peer review meetings. Following Stage 2, there have been further improvements to the peer review form regarding patient documentation. This change will be evaluated in two years time.

\section{REFERENCE}

1. Libell N. Peer review in Safeguarding. https://www.rcpch.ac.uk/sites/default/files/ page/Peer\%20review\%20final.pdf (Accessed: 15 August 2017)

\section{G145 AN AUDIT OF ADEHERENCE TO SKELETAL SURVEY GUIDANCE IN SUSPECTED NON-ACCIDENTAL INJURY IN CHILDREN UNDER TWO YEARS OR AGE}

${ }^{1}$ KK Tsang, ${ }^{2} \mathrm{~K}$ McKay, ${ }^{3} \mathrm{OG}$ Forbes. ${ }^{1}$ College of Medical, Vetinary and Life Sciences, University of Glasgow, Glasgow, UK; ${ }^{2}$ Child Protection Unit, Royal Hospital for Children, Glasgow, UK; ${ }^{3}$ Paediatrics, Royal Hospital for Children, Glasgow, UK

\subsection{6/archdischild-2018-rcpch.141}

Aim To audit compliance with local policy and RCPCH/RCR recommendation that all children under the age of two year who have a skeletal survey as part of a child protection investigation have follow up radiological imaging (either a full skeletal survey or chest $\mathrm{x}$-ray with oblique view of ribs) two weeks after initial imaging. In addition we aimed to assess the value of the skeletal survey in terms of identifying new injuries in children in our busy paediatric hospital.

Methods A five year (2012-2016 inclusive) retrospective analysis of radiology records and electronically archived in-patient notes was performed for all children under the age of two who underwent skeletal surveys as part of a child protection investigation. Reports of all skeletal surveys were analysed and cases where new injuries were identified were recorded. The standard was that all children had repeat imaging at 14 days 